\title{
Erratum to: Sevelamer is cost effective versus calcium carbonate for the first-line treatment of hyperphosphatemia in new patients to hemodialysis: a patient-level economic evaluation of the INDEPENDENT-HD study
}

\author{
Matteo Ruggeri · Antonio Bellasi • Filippo Cipriani • \\ Donald Molony $\cdot$ Cynthia Bell $\cdot$ Domenico Russo • \\ Biagio Di Iorio
}

Published online: 7 August 2014

(C) Italian Society of Nephrology 2014

\section{Erratum to: J Nephrol}

DOI 10.1007/s40620-014-0122-8

The number of patients lost to follow-up was 69 and not 68, 33 in the Sevelamer arm of the study and 36 (not 35) in the calcium carbonate arm. Supplementary Table 2 was also affected by this error and has been amended.

The online version of the original article can be found under doi:10.1007/s40620-014-0122-8.

Electronic supplementary material The online version of this article (doi:10.1007/s40620-014-0128-2) contains supplementary material, which is available to authorized users.

\section{Ruggeri}

Faculty of Economics, Università Cattolica del Sacro Cuore,

Rome, Italy

\section{A. Bellasi}

Division of Nephrology, Sant'Anna Hospital, Como, Italy
A. Bellasi
Department of Health Sciences, University of Milan, Milan, Italy
F. Cipriani
Market Access and Corporate Affairs, Genzyme, Italy
D. Molony
Division of Renal Dis and Hypertension, Department of Medicine, University of Texas Houston Medical School, Houston, TX, USA

\section{Bell}

Division of Pediatric Nephrology, Department of Pediatrics, University of Texas Houston Medical School, Houston, TX, USA

D. Russo

Department of Nephrology, School of Medicine,

Federico II University, Naples, Italy

B. Di Iorio $(\square)$

Department of Nephrology, Ospedale A. Landolfi di Solofra, Solofra (AV), Italy

e-mail: br.diiorio@gmail.com 